\title{
Correction \\ Correction: Huang et al. High-Uniform and High-Efficient Color Conversion Nanoporous GaN-Based Micro-LED Display with Embedded Quantum Dots. Nanomaterials 2021, 11, 2696
}

\author{
Yu-Ming Huang 1,2,3 ${ }^{\mathbb{D}}$, Jo-Hsiang Chen ${ }^{1}$, Yu-Hau Liou ${ }^{1}$, Konthoujam James Singh ${ }^{1} \mathbb{D}$, Wei-Cheng Tsai ${ }^{1}$, \\ Jung Han ${ }^{4}$, Chun-Jung Lin ${ }^{1}$, Tsung-Sheng Kao ${ }^{1}$, Chien-Chung Lin ${ }^{2,5, * \mathbb{D}}$, Shih-Chen Chen ${ }^{3, *}$ \\ and Hao-Chung Kuo ${ }^{1,3, * \mathbb{D}}$
}

Citation: Huang, Y.-M.; Chen, J.-H.; Liou, Y.-H.; James Singh, K.; Tsai, W.-C.; Han, J.; Lin, C.-J.; Kao, T.-S.; Lin, C.-C.; Chen, S.-C.; et al.

Correction: Huang et al.

High-Uniform and High-Efficient

Color Conversion Nanoporous

GaN-Based Micro-LED Display with

Embedded Quantum Dots.

Nanomaterials 2021, 11, 2696.

Nanomaterials 2022, 12, 252. https://

doi.org/10.3390/nano12020252

Received: 29 December 2021

Accepted: 7 January 2022

Published: 14 January 2022

Publisher's Note: MDPI stays neutral with regard to jurisdictional claims in published maps and institutional affiliations.
1 Department of Photonics, Institute of Electro-Optical Engineering, National Yang Ming Chiao Tung University, Hsinchu 30010, Taiwan; s101328035@gmail.com (Y.-M.H.); kingko56@yahoo.com.tw (J.-H.C.); randyliouyuhau@gmail.com (Y.-H.L.); jamesk231996@gmail.com (K.J.S.); jj510382.ee10@nycu.edu.tw (W.-C.T.); 18618135355@flexpn.com (C.-J.L.); tskao@nycu.edu.tw (T.-S.K.)

2 Institute of Photonic System, National Yang Ming Chiao Tung University, Tainan 71150, Taiwan

3 Semiconductor Research Center, Hon Hai Research Institute, Taipei 11492, Taiwan

4 Department of Electrical Engineering, Yale University, New Haven, CT 06520, USA; jung.han@yale.edu

5 Graduate Institute of Photonics and Optoelectronics, National Taiwan University, Taipei 10617, Taiwan

* Correspondence: chienchunglin@nctu.edu.tw (C.-C.L.); gary.sc.chen@foxconn.com (S.-C.C.); hckuo@faculty.nctu.edu.tw (H.-C.K.)

The authors wish to make following corrections in this paper [1].

\section{Authorship Correction}

Shih-Chen Chen is included as a corresponding author in the updated publication.

\section{Text Correction}

There was an error in the original publication. In the first paragraph of page 7 , in the sentence "The LCE of NP-GaN structure is found to be enhanced by $66.2 \%$ for green QD and $124.0 \%$ for red QD", the $124.0 \%$ should be changed to $52.7 \%$.

In Figure 5c,f, the LCE of the red QD film and red NPQD are $62.9 \%$ and $96.1 \%$. As a result, the enhancement is $52.7 \%$, not $124.0 \%$.

This change does not affect the scientific results or conclusions in the original published paper.

The authors would like to apologize for any inconvenience caused to the reader by making this change.

\section{Reference}

1. Huang, Y.-M.; Chen, J.-H.; Liou, Y.-H.; James Singh, K.; Tsai, W.-C.; Han, J.; Lin, C.-J.; Kao, T.-S.; Lin, C.-C.; Chen, S.-C.; et al. High-Uniform and High-Efficient Color Conversion Nanoporous GaN-Based Micro-LED Display with Embedded Quantum Dots. Nanomaterials 2021, 11, 2696. [CrossRef] [PubMed]
Copyright: (c) 2022 by the authors Licensee MDPI, Basel, Switzerland. This article is an open access article distributed under the terms and conditions of the Creative Commons Attribution (CC BY) license (https:// creativecommons.org/licenses/by/ $4.0 /)$. 